\title{
Psoralea corylifolia L. Seed Extract Ameliorates Streptozotocin-Induced Diabetes in Mice by Inhibition of Oxidative Stress
}

\author{
Eunhui Seo, ${ }^{1,2}$ Eun-Kyu Lee, ${ }^{1,2}$ Cheol Soon Lee, ${ }^{3}$ Kwang-Hoon Chun, ${ }^{1}$ \\ Mi-Young Lee, ${ }^{4}$ and Hee-Sook Jun ${ }^{1,2,5}$ \\ ${ }^{1}$ College of Pharmacy and Gachon Institute of Pharmaceutical Science, Gachon University, Incheon 406-840, Republic of Korea \\ ${ }^{2}$ Lee Gil Ya Cancer and Diabetes Institute, Gachon University, Incheon 406-840, Republic of Korea \\ ${ }^{3}$ Nanomol Inc. and Regen Phoenix R\&D Institute, Incheon 406-840, Republic of Korea \\ ${ }^{4}$ KM-Based Herbal Drug Research Group, Korea Institute of Oriental Medicine, Daejeon 305-811, Republic of Korea \\ ${ }^{5}$ Gachon Medical Research Institute, Gil Hospital, Incheon 405-760, Republic of Korea \\ Correspondence should be addressed to Hee-Sook Jun; hsjun@gachon.ac.kr
}

Received 26 December 2013; Revised 4 March 2014; Accepted 8 March 2014; Published 3 April 2014

Academic Editor: Felipe Dal-Pizzol

Copyright (C) 2014 Eunhui Seo et al. This is an open access article distributed under the Creative Commons Attribution License, which permits unrestricted use, distribution, and reproduction in any medium, provided the original work is properly cited.

Pancreatic beta-cell death is known to be the cause of deficient insulin production in diabetes mellitus. Oxidative stress is one of the major causes of beta-cell death. In this study, we investigated the effects of Psoralea corylifolia L. seed (PCS) extract on betacell death. Oral administration of PCS extract resulted in a significant improvement of hyperglycemia in streptozotocin-induced diabetic mice. PCS extract treatment improved glucose tolerance and increased serum insulin levels. To study the mechanisms involved, we investigated the effects of PCS extract on $\mathrm{H}_{2} \mathrm{O}_{2}$-induced apoptosis in INS-1 cells. Treatment with PCS extract inhibited cell death. PCS extract treatment decreased reactive oxygen species level and activated antioxidative enzymes. Among the major components of PCS extract, psoralen and isopsoralen (coumarins), but not bakuchiol, showed preventive effects against $\mathrm{H}_{2} \mathrm{O}_{2}$ induced beta-cell death. These findings indicate that PCS extract may be a potential pharmacological agent to protect against pancreatic beta-cell damage caused by oxidative stress associated with diabetes.

\section{Introduction}

It is commonly known that beta-cell death plays an important role in the pathophysiological progression of both type 1 and type 2 diabetes [1-3]. Although the main cause is not yet clear, glucolipotoxicity, cytokines, and genetic factors are associated with beta-cell apoptosis [4]. These stimuli are known to induce oxidative stress leading to apoptosis of the pancreatic beta-cells [5-7]. In this regard, treatment with antioxidant agents such as $\mathrm{N}$-acetylcysteine, resveratrol, and $\alpha$-lipoic acid showed cytoprotective effects on dysfunctional or apoptotic beta-cells [7-9]. In addition, oxidative stress is involved in the progression of diabetic complications including cardiomyopathy, nephropathy, neuropathy, retinopathy, and vascular damage [10].
The seeds of Psoralea corylifolia (PCS), commonly known as "Boh-Gol-Zhee" in Korea, have been used in traditional medicine. Six compounds, bakuchiol, psoralen, isopsoralen, corylifolin, corylin, and psoralidin, are the major components of PCS extract and are potent antioxidants [11]. PCS extract is used to treat diseases such as leucoderma [12] and impotence [13] and has antitumor [14] and antibacterial effects $[15,16]$. In particular, bakuchiol, a polyphenol compound in PCS, has protective effects against hepatic injury $[17,18]$. Similarly, psoralen and isopsoralen, coumarins of PCS, have antitumor effects [19] and alleviate amnesia [20]. However, PCS extract has not been used for the treatment of diabetes, and the effect of PCS on beta-cells is not known. In this study, we examined whether PCS extract has preventive effects against beta-cell damage in streptozotocin- (STZ-) 
induced diabetes in mice and beta-cell apoptosis in vitro to determine whether it might be a potential pharmacological treatment for diabetes.

\section{Materials and Methods}

2.1. Materials. RPMI1640 medium and fetal bovine serum were purchased from Gibco BRL (Grand Island, NY). Antibodies against catalase, heme oxygenase- (HO-)1, and phosphorylated $5^{\prime}$ AMP-activated protein kinase $\alpha(\mathrm{pAMPK} \alpha)$ were obtained from Santa Cruz Biotechnology Inc. (Santa Cruz, CA). Antibodies against cleaved poly (ADP-ribose) polymerase (PARP), pro-PARP, cleaved caspase3, procaspase3, phosphorylated c-Jun N-terminal kinase (pJNK), and phosphorylated-p38 were obtained from Cell Signaling (Boston, MA). An antibody against actin was obtained from Sigma-Aldrich (St. Louis, MO). Horseradish peroxidaseconjugated secondary antibodies were obtained from Santa Cruz Biotechnology Inc. Bakuchiol was purchased from Enzo Life Sciences Inc. (Farmingdale, NY). STZ, resveratrol, psoralen, and isopsoralen were obtained from Sigma-Aldrich (St Louis, MO).

2.2. Preparation of PCS Extract. The PCS used in the present study was purchased from an oriental drug store (Kwang Myung Dang Co., Ulsan, Korea), and the voucher specimen was deposited in the Herbarium of Korea Institute of Oriental Medicine (KIOM) under the registration number KIOM111930. The extract was prepared by the standard procedure. In brief, the dried seeds ( $300 \mathrm{~g}$ ) were ground into small pieces and then extracted twice with distilled water under reflux. The combined water extract was evaporated in vacuo to give a dark brownish residue (61.92 g).

2.3. Cell Culture. INS-1 cells were maintained at subconfluence at $37^{\circ} \mathrm{C}$ with $5 \% \mathrm{CO}_{2}$. The cells were grown in RPMI1640 with $10 \%$ fetal bovine serum containing $50 \mu \mathrm{M}$ beta-mercaptoethanol and 100 units $/ \mathrm{mL}$ of penicillin and streptomycin. Cells were incubated with PCS extract (6.25$400 \mu \mathrm{g} / \mathrm{mL}$ ) or purified individual components of PCS extract $(0.5-4 \mu \mathrm{g} / \mathrm{mL})$ for $24 \mathrm{~h} . \mathrm{H}_{2} \mathrm{O}_{2}(100 \mu \mathrm{M})$ was added for the last 30 minutes or 1 hour of incubation. Resveratrol $(50 \mu \mathrm{M})$ was used as a positive control.

2.4. Animals. Six-week-old male C57BL/6 mice were supplied by the Orient Bio Inc. [13]. Animals were maintained at animal facilities at the Lee Gil Ya Cancer and Diabetes Institute, Gachon University of Medicine and Science, under a 12-h light and 12-h dark photoperiod. All animal experiments were carried out under a protocol approved by the Institutional Animal Care and Use Committee at Lee Gil Ya Cancer and Diabetes Institute, Gachon University. After adaptation for one week, mice were given an injection of $50 \mathrm{mg} / \mathrm{kg} /$ day i.p. STZ for 5 consecutive days. Age-matched control mice received an equal volume of vehicle. STZinjected mice were treated orally with PCS extract (200 or $500 \mathrm{mg} / \mathrm{kg} /$ day) or vehicle at the same as the STZ injections began, and treatments continued daily for 8 weeks.
2.5. Glucose Tolerance Tests. Animals were fasted overnight and glucose $(2 \mathrm{~g} / \mathrm{kg})$ was administered by intraperitoneal injection. Blood samples were obtained from the tail vein at $0,30,60,90,120,150$, and $180 \mathrm{~min}$ after glucose load. Blood glucose levels were measured with a glucose analyzer (OneTouch Ultra, Lifescan, Johnson \& Johnson, Milpitas, CA).

2.6. Measurement of Hemoglobin A1c (HbA1c) Levels. HbAlc measurements were made using an AU 680 chemistry analyzer (Beckman Coulter, Inc., Brea, CA) and an HbAlc APT kit (Beckman Coulter, Inc.) following the manufacturer's instructions. HbAlc $<6 \%$ is considered normal [21].

2.7. Measurement of Blood Glucose and Serum Insulin. Blood samples were collected to measure blood glucose and serum insulin. The blood sampling line was filled with a solution of $4.5 \%$ EDTA to prevent blood clotting. Samples were kept on ice, and plasma was isolated and stored at $-70^{\circ} \mathrm{C}$ until analysis. Glucose levels were measured with a glucose analyzer (OneTouch Ultra). Insulin levels were determined in duplicate using $5 \mu \mathrm{L}$ of serum and an Ultrasensitive Mouse Insulin kit (ALPCO, Windham, NH) according to the manufacturer's instructions.

2.8. Immunohistochemical and Histological Staining of Pancreatic Sections. Mice were killed and pancreatic specimens were removed, fixed in 10\% formalin, and embedded in paraffin. For insulin staining, frozen sections were incubated for 16 hours with guinea pig polyclonal antibodies against insulin (Dako, Carpenteria, CA) diluted 1:100 in 0.1\% PBS containing $0.3 \%$ TritonX-100 at $4^{\circ} \mathrm{C}$. Horseradish peroxidaseconjugated secondary antibodies were incubated for 1 hour at room temperature and visualized using diaminobenzidine (Dako). Slides were counterstained with haematoxylin dehydrated sequentially in ethanol, cleared with xylenes, and mounted.

2.9. Western Blotting. Cells were solubilized with mammalian protein extraction buffer (GE Healthcare, Milwaukee, WI) containing a protease and phosphatase inhibitor cocktail (Sigma-Aldrich). Proteins (30-50 $\mu \mathrm{g}$ ) were resolved by 8 or $15 \%$ sodium dodecyl sulfate polyacrylamide gel electrophoresis, transferred onto membranes, and blocked with trisbuffered saline containing Tween 20 in 5\% nonfat dry milk. The membranes were incubated with specific primary antibodies and visualized by incubating with horseradish peroxidase-conjugated secondary antibodies. Chemiluminescence was detected by LAS-4000 (Fuji Film, Tokyo, Japan) after adding Immobilon Western chemiluminescent HRP substrate (Millipore, St. Charles, MO). The images derived from western blotting were analyzed through ImageJ (National Institutes of Health, Bethesda, MD) software for Windows. Each densitometric value was normalized to $\beta$ actin.

2.10. Reactive Oxygen Species Detection. For quantification of intracellular reactive oxygen species (ROS) levels, cells 
were loaded with $10 \mu \mathrm{M} 2^{\prime}, 7^{\prime}$-dichlorodihydrofluorenscein diacetate (Molecular Probes, Eugene, OR) for $30 \mathrm{~min}$ at $37^{\circ} \mathrm{C}$ and $5 \% \mathrm{CO}_{2}$ in phosphate-buffered saline (PBS). Cells were collected and washed twice with PBS and suspended in $500 \mu \mathrm{L}$ PBS. Mean fluorescence intensity was used as a measure of ROS as determined by flow cytometry FACSCalibur (BD Biosciences, San Jose, CA) using CellQuest Pro 5.2 with an excitation wavelength of $485 \mathrm{~nm}$ and an emission wavelength of $530 \mathrm{~nm}$.

2.11. Superoxide Dismutase and Glutathione Peroxidase Activity Measurements. Superoxide dismutase (SOD) and glutathione peroxidase [22] activities were determined using a Superoxide Dismutase assay kit and Glutathione Peroxidase assay kit, respectively, following the manufacturer's instructions (Cayman Chemical, Ann Arbor, MI).

2.12. Measurement of Viable Cell Numbers. The number of viable cells was measured by a CCK- 8 assay kit (Dojindo Laboratories, Kumamoto, Japan). Briefly, $10 \mu \mathrm{L}$ of CCK-8 dye and $100 \mu \mathrm{L}$ of cell culture medium were added to each well and incubated for $2 \mathrm{~h}$ at $37^{\circ} \mathrm{C}$. Plates were then analyzed with a VERSAmax microplate reader (Molecular Devices Sunnyvale, CA). Measurements of formazan dye absorbance were carried out at $450 \mathrm{~nm}$, with the reference wavelength at $620 \mathrm{~nm}$. The number of viable cells after each treatment was normalized as a percentage of the number of viable cells in the control group.

2.13. Liquid Chromatography-Mass Spectrometry Analysis. Liquid chromatography-mass spectrometry analysis of PCS extract was performed on an Ultimate 3000 HPLC system combined with a Q Exactive Orbitrap mass spectrometer from Thermo Fisher Scientific (Bremen, Germany). A CSH C18 column $(70 \times 2.1 \mathrm{~mm}, 1.7 \mu \mathrm{m})$ (Waters, Milford, MA) was employed for reverse phase separations. The mobile phases were $0.1 \% \mathrm{v} / \mathrm{v}$ formic acid in water and $0.1 \% \mathrm{v} / \mathrm{v}$ formic acid in acetonitrile. The elution gradient for the CSH $\mathrm{C} 18$ condition was programed as increasing percentage of B from $0 \%$ to $40 \%$ in 9 minutes, holding at $100 \%$ of B for 1 minute, and finally reequilibrating the column at $0 \%$ for 3 minutes. The electrospray ionization interface was operated in positive polarity mode. The spray voltage was $3.5 \mathrm{kV}$. The temperature of the ion transfer capillary was $350^{\circ} \mathrm{C}$ and sheath and auxiliary gases were 50 and 10 arbitrary units, respectively. The full scan range was 50 to $750 \mathrm{~m} / \mathrm{z}$ with automatic gain control target and resolution settings as $1 e^{6}$ and 140,000, respectively. The selective $\mathrm{MS}^{2}$ fragmentation of psoralen and isopsoralen was carried out by using higher collisional induced dissociation at $60 \mathrm{~V}$.

2.14. Statistical Analyses. All data are expressed as mean \pm standard error of at least three independent experiments. Data were analyzed using Analysis of Variance followed by posthoc analysis using the Tukey range test (SPSS 10.0 statistical software). $P$ values less than 0.05 were considered statistically significant.

\section{Results}

3.1. Effect of PCS Extract on Prevention of STZ-Induced Diabetes. To determine the effect of PCS extract on the prevention of beta-cell damage, we injected STZ ( $50 \mathrm{mg} / \mathrm{kg}$ i.p. for 5 days) and administered PCS extract (200 or $500 \mathrm{mg} / \mathrm{kg} /$ day) for 8 weeks beginning on the same day as the first STZ injection and monitored body weight changes, HbAlc levels, and blood glucose levels. As shown in Figure 1(a), induction of diabetes by STZ caused a significant weight loss, and administration of PCS extract at $500 \mathrm{mg} / \mathrm{kg} /$ day significantly reduced the weight loss in STZ-injected mice at 4 and 8 weeks after treatment (Figure 1(a)). HbAlc levels were significantly lower in PCS extract-treated diabetic mice as compared with PBS-treated diabetic mice (Figure 1(b)). Similarly, both nonfasting (Figure 1(c)) and fasting (Figure 1(d)) blood glucose levels in PCS extract-treated diabetic mice were significantly lower than PBS-treated diabetic mice at 8 weeks after treatment.

To assess the effect on glucose regulation in PCS extracttreated diabetic mice, we performed intraperitoneal glucose tolerance tests. As shown in Figure 1(e), a glucose load given to the normal control group produced a rapid increase in blood glucose levels at $30 \mathrm{~min}$ which returned to baseline values within $120 \mathrm{~min}$. After glucose loading, all STZ-induced diabetic mice showed hyperglycemia above $400 \mathrm{mg} / \mathrm{dL}$ at all measurement times. However, treatment of diabetic mice with $500 \mathrm{mg} / \mathrm{kg} /$ day of PCS extract resulted in a significant improvement in glucose tolerance compared with the vehicletreated group (Figure 1(f)).

\subsection{Effect of PCS Extract on Prevention of Pancreatic $\beta$ -} Cell Damage by STZ Treatment. As blood glucose levels were significantly lower in PCS extract-treated diabetic mice than in PBS-treated diabetic mice, we examined whether this effect was due to the reduction of pancreatic beta-cell damage caused by STZ injection. Serum insulin was significantly decreased in STZ-induced diabetic mice; however, administration of $500 \mathrm{mg} / \mathrm{kg} /$ day of PCS extract significantly inhibited this decrease of plasma insulin levels (Figure 2(a)). The pancreatic islets of vehicle-treated diabetic mice revealed small, atrophied islets that showed light staining with antiinsulin antibody, ambiguity of their verges, and degranulation of cells (Figure 2(b)). PCS extract-treated diabetic mice showed stronger staining with anti-insulin antibody, larger islets, and fewer degenerative changes compared with the PBS-treated group (Figure 2(b)).

3.3. Effect of PCS Extract on $\mathrm{H}_{2} \mathrm{O}_{2}$-Induced Apoptosis in INS1 Cells. To investigate whether PCS extract has protective effect on oxidative stress-induced beta-cell apoptosis, we examined the effects of PCS extract on cell death in $\mathrm{H}_{2} \mathrm{O}_{2}$ treated INS-1 cells. Western blot analysis of cleaved PARP and cleaved caspase-3, apoptosis-related proteins, showed that $\mathrm{H}_{2} \mathrm{O}_{2}$ treatment increased the expression of these proteins, and PCS extract pretreatment inhibited this increase in a dose-dependent manner. Mitogen-activated protein kinases (MAPK) are key molecules in the apoptotic signaling 


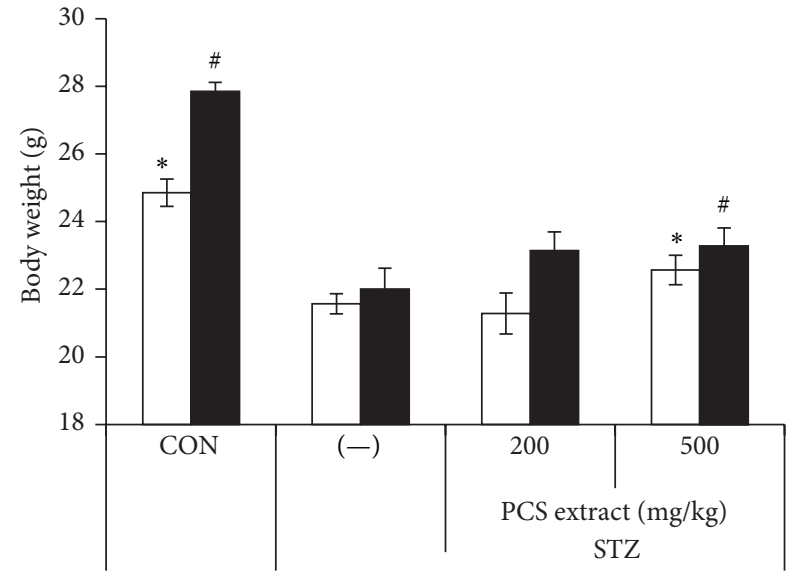

4 weeks

8 weeks

(a)

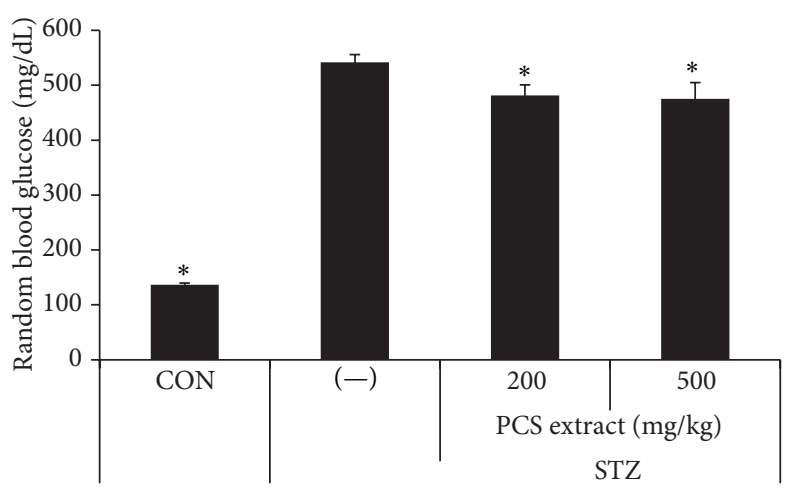

(c)

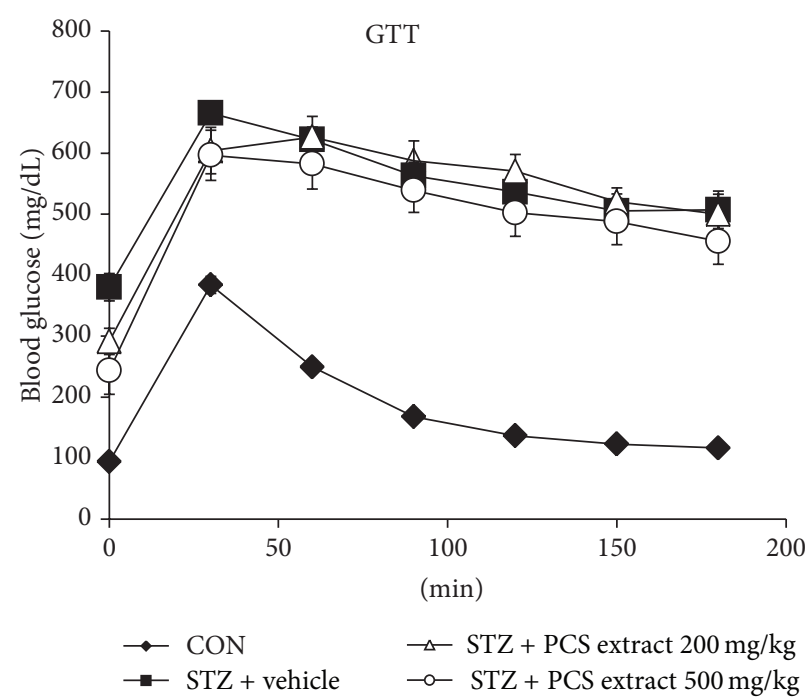

(e)

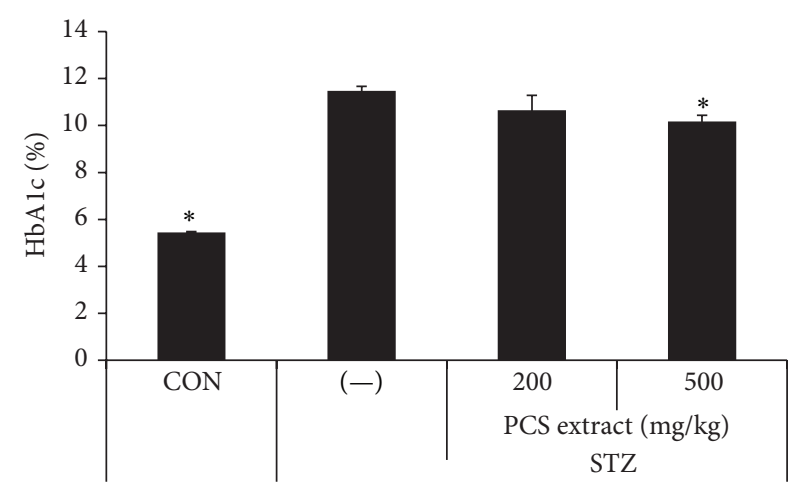

(b)

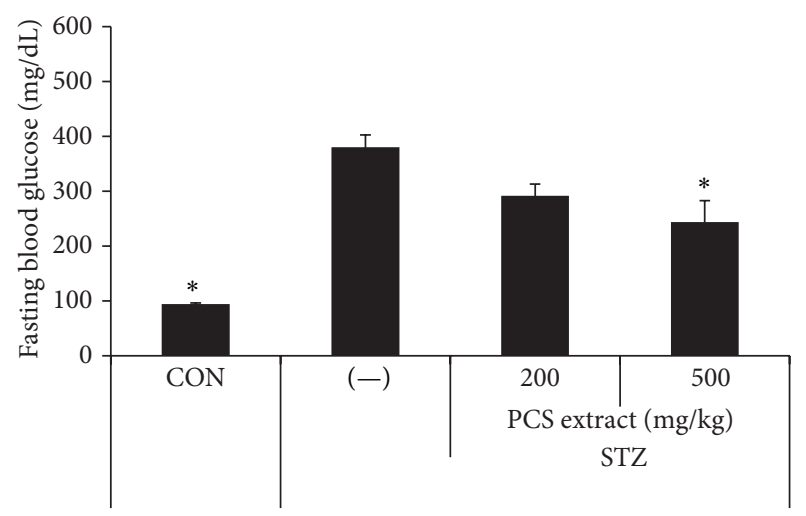

(d)

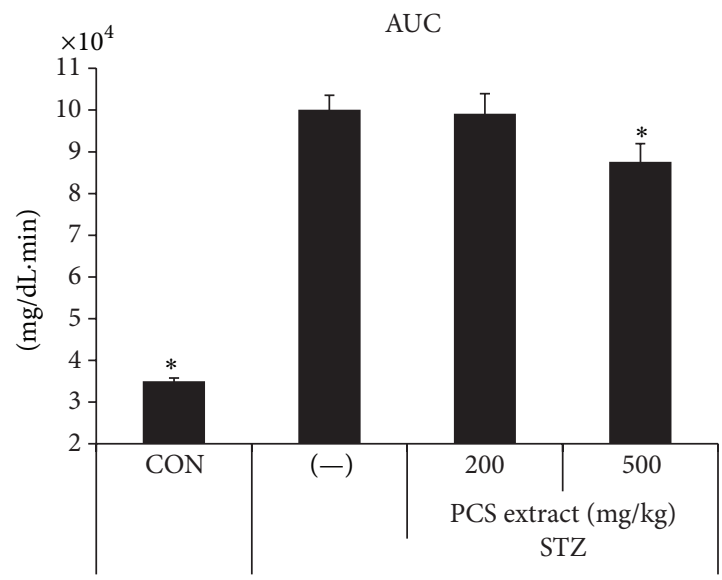

(f)

FIGURE 1: Amelioration of STZ-induced hyperglycemia by PCS extract. Mice were injected with vehicle (CON) or STZ (50 mg/kg/day) for 5 consecutive days. STZ-injected mice were treated with vehicle $(-)$ or PCS extract $(200$ or $500 \mathrm{mg} / \mathrm{kg} / \mathrm{day})$ for 8 weeks beginning on the first day of STZ injection. (a) Body weight at 4 and 8 weeks after PCS extract treatment. ${ }^{*} P<0.05$ versus $(-) /$ STZ mice at 4 weeks. ${ }^{\#} P<0.05$ versus $(-) /$ STZ mice at 8 weeks. (b) HbAlc levels. (c) Random blood glucose levels. (d) Fasting blood glucose levels after 8 weeks of PCS extract treatment. (e) Glucose tolerance test (GTT). Mice were fasted overnight and glucose ( $2 \mathrm{~g} / \mathrm{kg}$ i.p.) was administered. Blood glucose levels were measured at the indicated times after glucose load. (f) Area under the curve (AUC) of the GTT graph. ${ }^{*} P<0.05$ versus $(-) /$ STZ mice. 


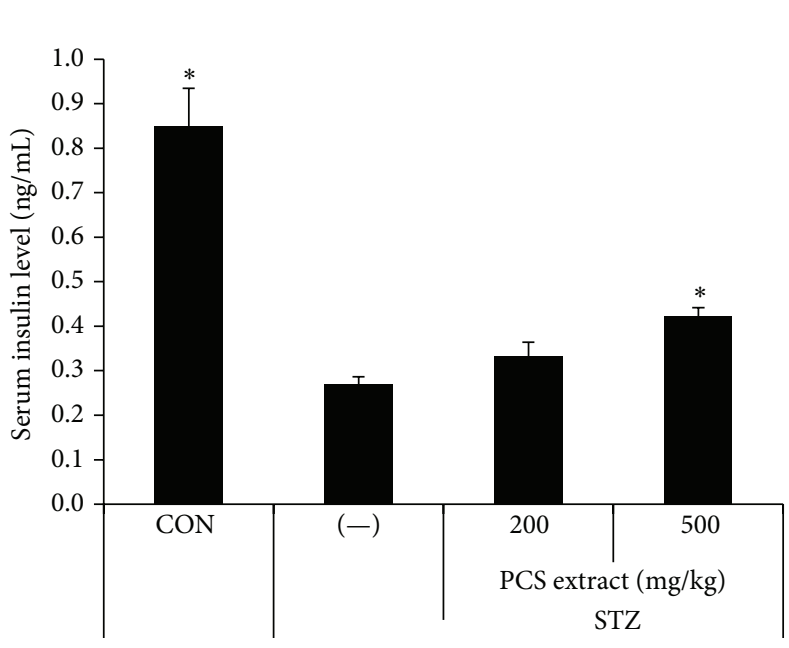

(a)
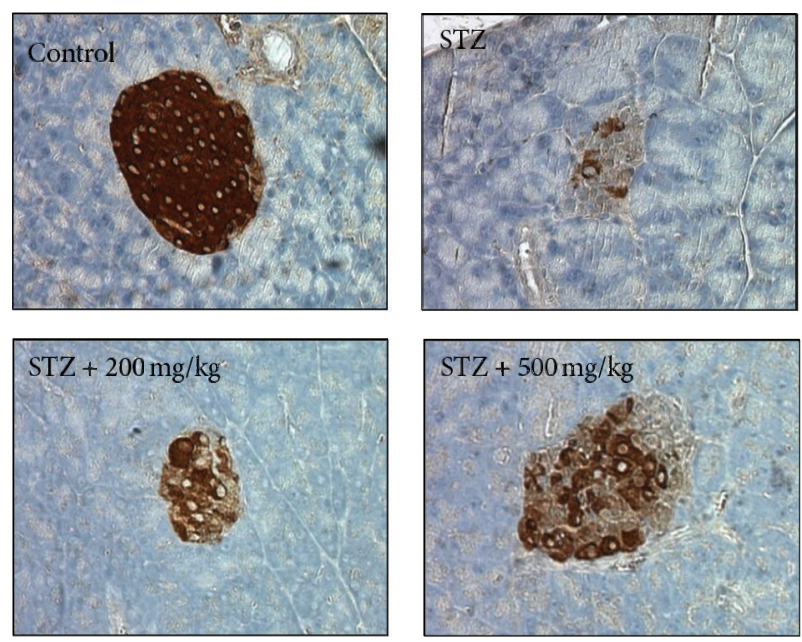

(b)

FIGURE 2: Reduction of STZ-induced beta-cell damage by PCS extract. Mice were injected with vehicle (CON) or STZ (50 mg/kg/day) for 5 consecutive days. STZ-injected mice were treated with vehicle (-) or PCS extract ( $200 \mathrm{or} 500 \mathrm{mg} / \mathrm{kg} /$ day) for 8 weeks beginning on the first day of STZ injection. (a) Serum insulin level after 8 weeks of PCS extract treatment. ${ }^{*} P<0.05$ versus (-)/STZ mice. (b) Pancreatic sections stained with anti-insulin antibody.

pathways, and ROS are known to induce MAPK signaling pathway activation [2]. Thus, we also checked phosphorylated p38 MAPK and p-JNK and found that the expression of these proteins was similarly inhibited by PCS extract pretreatment (Figure 3(a)).

3.4. Antioxidative Effects of PCS Extract in INS-1 Cells. To examine whether PCS extract has free radical scavenging effects, we measured the intracellular ROS level in INS-1 cells after treatment with $\mathrm{H}_{2} \mathrm{O}_{2}$ in the presence or absence of PCS extract. The ROS level was significantly reduced by $50 \mu \mathrm{g}$ PCS extract and was not further reduced by higher doses of PCS extract (Figure 3(b)). Antioxidative enzymes such as GPX and SOD remove ROS and protect cells from oxidative damage, and AMPK is known to maintain metabolic homeostasis. Heme oxygenase-1 (HO-1) is also an antioxidative protein induced in response to a variety of oxidative stresses. We found that HO-1 and pAMPK protein levels were increased by the addition of PCS extract (Figure 3(c)). The activities of GPX (Figure 3(d)) and SOD (Figure 3(e)) were also unchanged by $\mathrm{H}_{2} \mathrm{O}_{2}$ treatment alone but were significantly increased by the addition of PCS extract.

3.5. Effects of Bakuchiol, Psolaren, and Isopsolaren on $\mathrm{H}_{2} \mathrm{O}_{2}$ Induced Beta-Cell Death. Bakuchiol, psoralen, and isopsoralen are known to be active components of PCS extract. To determine whether any of these compounds might be responsible for the antiapoptotic effect of PCS extract in $\mathrm{H}_{2} \mathrm{O}_{2}$-induced beta-cell death, we examined the antiapoptotic effects of purified bakuchiol, psoralen, and isopsoralen on INS-1 cells. As shown in Figure 4, INS-1 cells treated with $\mathrm{H}_{2} \mathrm{O}_{2}$ showed reduced cell viability by approximately $60 \%$ relative to control cells. When the cells were pretreated with
PCS extract, the cell survival rate increased dose dependently (Figure 4(a)). The $\mathrm{H}_{2} \mathrm{O}_{2}$-induced cytotoxic effect was not affected by cotreatment with bakuchiol (Figure 4(b)) but was significantly attenuated by cotreatment with psoralen (Figure 4(c)) or isopsoralen (Figure 4(d)).

3.6. Identification of Psoralen and Isopsoralen in PCS Extracts. To determine whether psoralen and isopsoralen are present in the PCS extracts used in this study, PCS extracts $(100 \mu \mathrm{g} / \mathrm{mL})$ were run on the HPLC-Q Exactive Orbitrap mass spectrometer in a scan and MS2 mode (Figure 4(e)). Extracted ion chromatogram $([\mathrm{M}+\mathrm{H}]=187.0386)$ for psoralen and isopsoralen showed that both compounds were present in our PCS extracts. Psoralen and isopsoralen were separated and eluted at $7.59 \mathrm{~min}$ and $7.84 \mathrm{~min}$, respectively. The $\mathrm{MS}^{2}$ spectrum for psoralen and isopsoralen further confirmed that both compounds were present in PCS extracts.

\section{Discussion}

Psoralea corylifolia L. seeds (PCS), commonly known as "Boh-Gol-Zhee" in Korea, have been used in traditional medicine for joint and back pain as well as other conditions. These seeds have been widely studied for their antitumor, antioxidant, antimicrobial, and anti-inflammatory effects [12, $15,19,23]$. In our previous study, PCS extract also showed antisenescence effects in human dermal fibroblasts [24]. It is well known that oxidative stress is related to cellular senescence and aging [25]. Similarly, most components of PCS are potent antioxidants $[11,23,26]$. The antioxidant activities of the compounds decrease in the following order: psoralidin $>$ bakuchiol $>$ corylifolin $>$ corylin $>$ isopsoralen $=$ psoralen [11]. The antioxidative properties of PCS make it of 

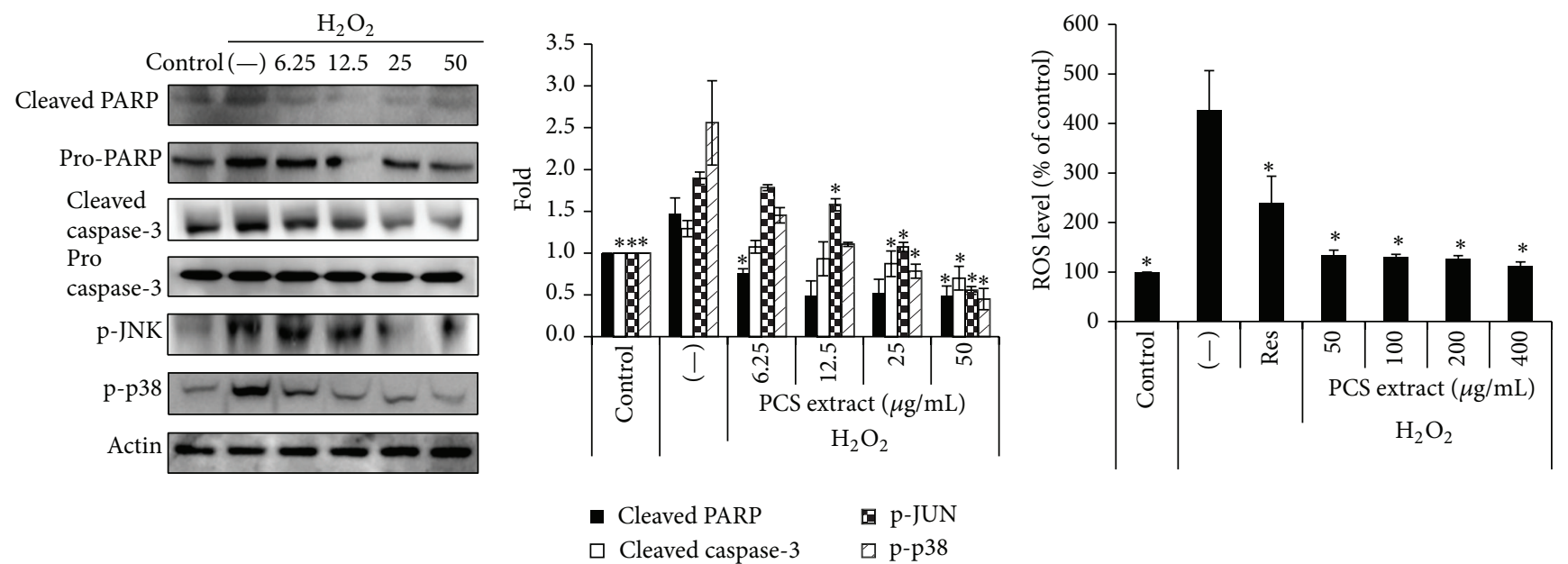

(a)

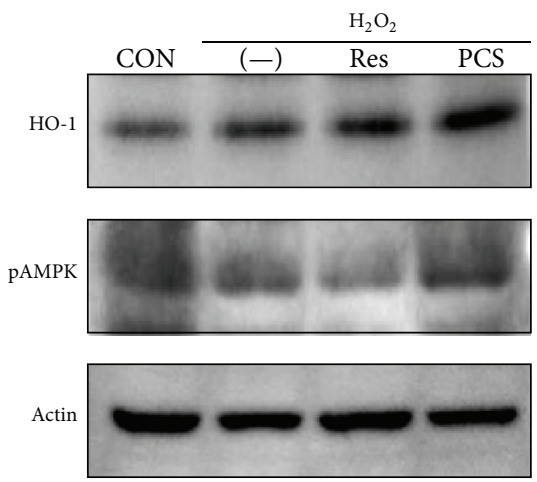

(c)

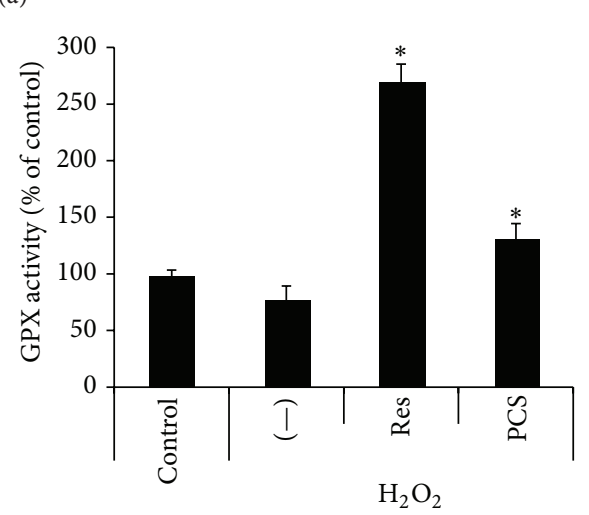

(d)

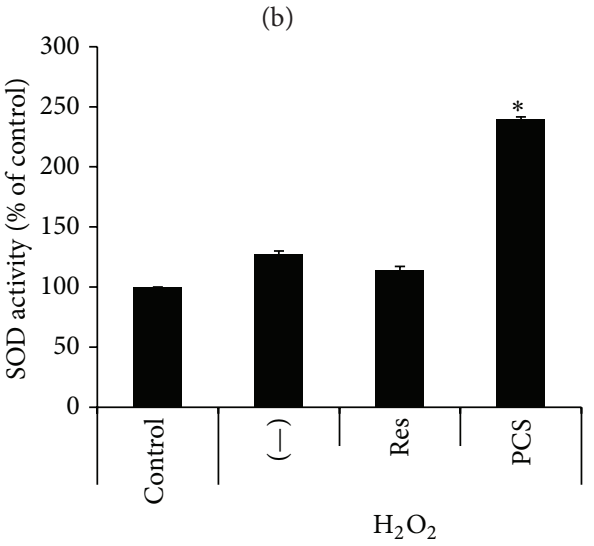

(e)

FIgURE 3: Antiapoptotic and antioxidative effect of PCS extract in $\mathrm{H}_{2} \mathrm{O}_{2}$-treated INS-1 cells. INS-1 cells were treated without (-) or with various doses of PCS extract for $24 \mathrm{~h}$, and $100 \mu \mathrm{M} \mathrm{H}_{2} \mathrm{O}_{2}$ was added for the last $1 \mathrm{~h}$ (a) or $30 \mathrm{~min}$ ((b)-(d)). (a) Protein levels of apoptotic signaling pathway were analyzed using western blotting. The representative blots (left) and the quantitative analysis of the band intensity by densitomery (right). The data are presented as a ratio of control. (b) ROS levels were measured. (c) Levels of anti-oxidative related proteins were analyzed using western blotting. (d), (e) GPX activity and SOD activity were measured. Resveratrol (Res) was used as a positive control. ${ }^{*} \mathrm{P}<0.05$ versus $(-) / \mathrm{H}_{2} \mathrm{O}_{2}$.

interest with regard to possible beneficial effects on oxidative stress-related diseases.

In both type 1 and type 2 diabetes, oxidative stress is thought to mediate beta-cell death, by inflammatory processes in the case of type 1 diabetes and by chronic hyperglycemia in the case of type 2 diabetes [5, 7, 27]. Diabetes increases the production of tissue-damaging ROS by glucose autoxidation and nonenzymatic protein glycosylation. Thus, protecting beta-cells against damage induced by oxidative stress is an important strategy for the treatment of diabetes. PCS have been used traditionally as a medicine in Asia and are known to have antioxidant activity $[23,26]$. In this study, we investigated the protective effects of PCS extracts against beta-cells apoptosis induced by oxidative stress using STZ-induced diabetic mice as an animal model. Although this animal model does not mimic either the autoimmune destruction of beta-cells found in type 1 diabetes or the insulin resistance found in type 2 diabetes, STZ does substantially increase the ROS level in the pancreas and cause selective pancreatic beta-cell death $[28,29]$, thus providing a model in which the possible protective effect of PCS can be studied.

We found that STZ injection into C57BL/6 mice led to body weight loss, hyperglycemia, and hypoinsulinemia, all of which were significantly ameliorated by administration of PCS extract at $500 \mathrm{mg} / \mathrm{kg} /$ day. Although significant, the effects of PCS on blood glucose were relatively mild and did not completely restore normoglycemia. Furthermore, our histological study showed a protective effect of PCS extract on pancreatic islet structure and insulin staining. These data suggest that PCS extract reduces the diabetic symptoms and pancreatic damage induced by STZ.

Oxidative stress can activate mitogen-activated protein kinase (MAPK) cascades, including JNK and p38 MAPK [30], and antioxidant treatment prevents MAPK activation and beta-cell apoptosis [31]. These proteins mediate many 


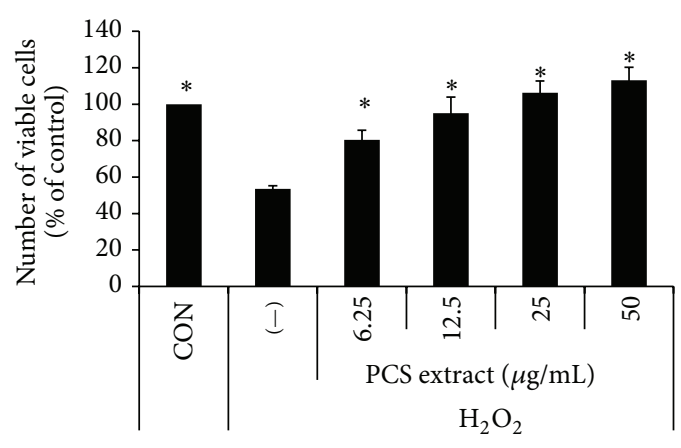

(a)

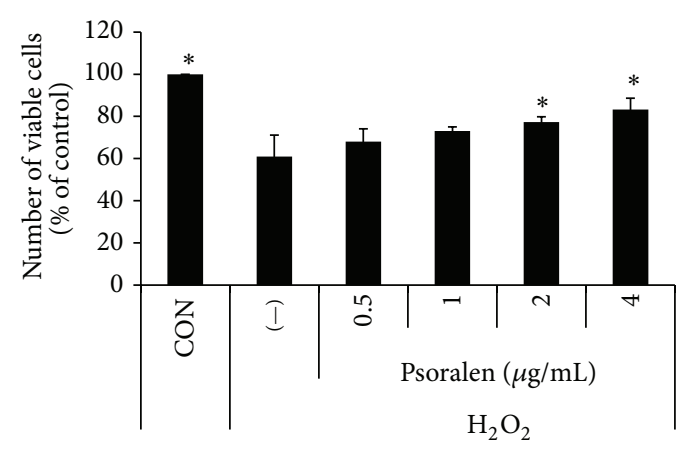

(c)

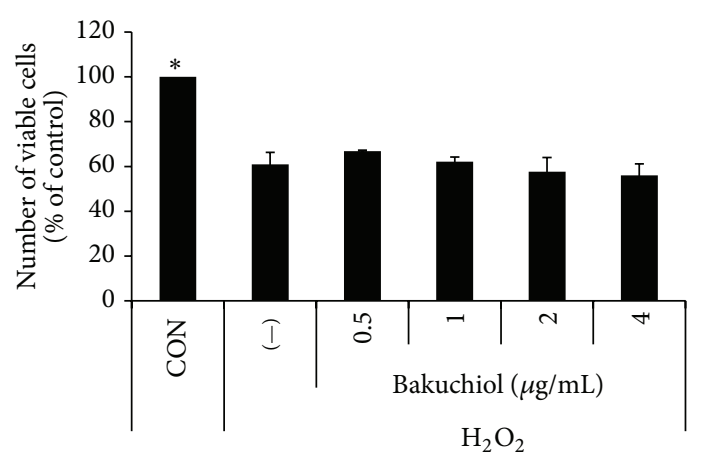

(b)

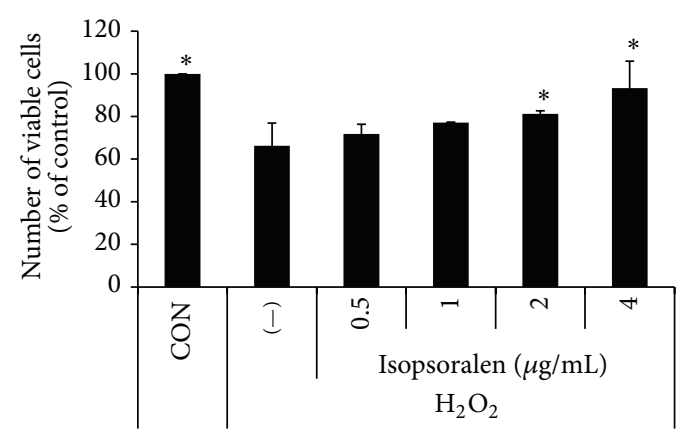

(d)

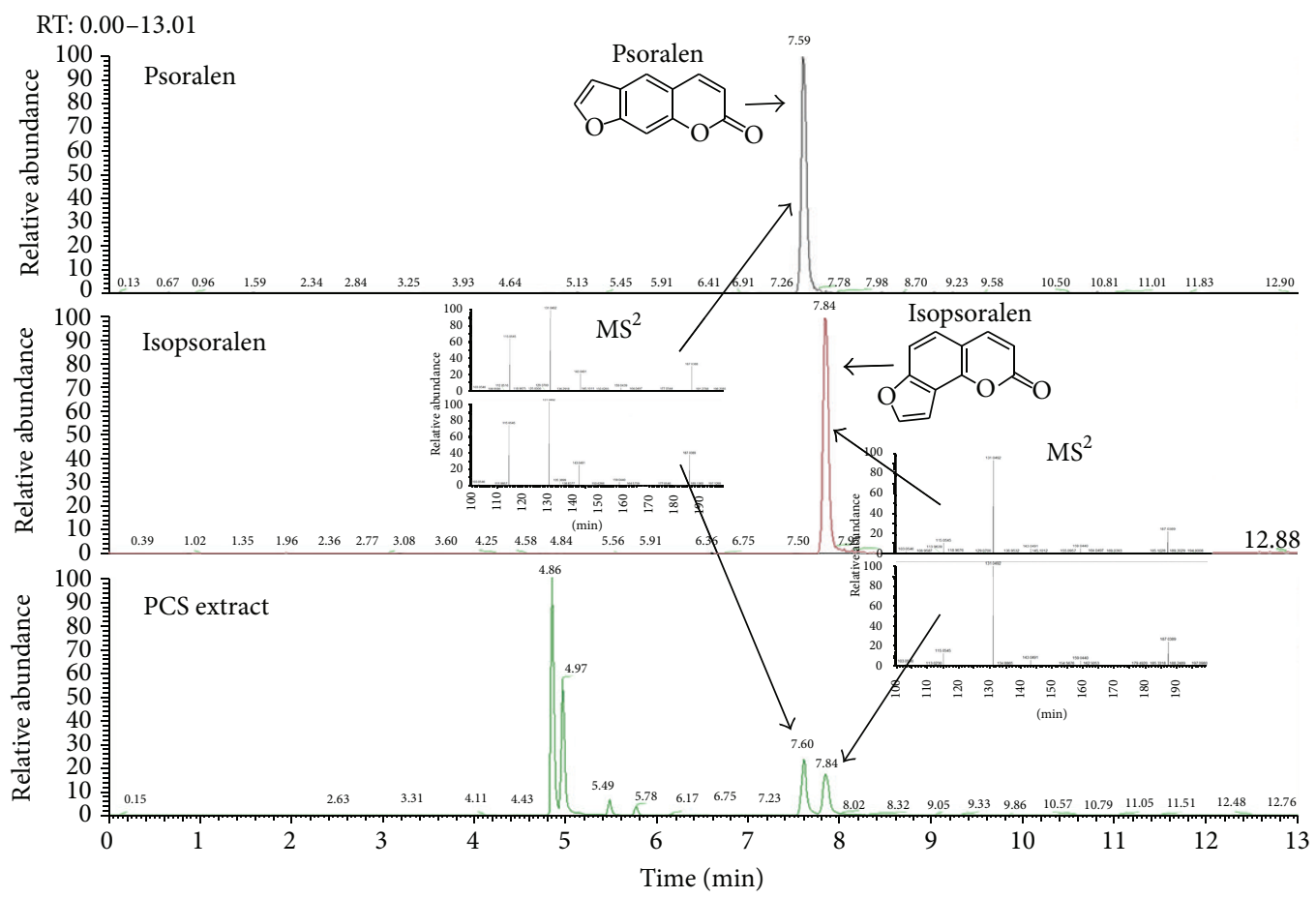

(e)

FIGURE 4: Antiapoptotic effect of psolaren and isopsolaren, PCS extract components, in $\mathrm{H}_{2} \mathrm{O}_{2}$-treated INS-1 cells. (a)-(d) INS-1 cells were treated without (-) or with various doses of PCS extract (a) or components of PCS extract ((b) bakuchiol, (c) psoralen, and (d) isopsoralen) for $24 \mathrm{~h}$, and $100 \mu \mathrm{M} \mathrm{H}_{2} \mathrm{O}_{2}$ was added for the last $1 \mathrm{~h}$. Cell viability was measured by a CCK-8 assay kit. ${ }^{*} P<0.05$ versus $(-) / \mathrm{H}_{2} \mathrm{O}_{2}$. (e) Extracted ion chromatograms and $\mathrm{MS}^{2}$ spectrums for psoralen and isopsoralen. Ion chromatograms $([\mathrm{M}+\mathrm{H}]=187.0386)$ were extracted from psoralen $(1 \mu \mathrm{g} / \mathrm{mL})$, isopsoralen $(1 \mu \mathrm{g} / \mathrm{mL})$, and PCS extract $(100 \mu \mathrm{g} / \mathrm{mL})$ chromatograms. MS ${ }^{2}$ spectrums were obtained from each compound and PCS extract. 
important signals in mammalian cells, including cell proliferation, differentiation, and apoptosis. Similarly, MAPK activation contributes to pancreatic beta-cell dysfunction and apoptosis through PARP and capase-3 cascade signaling. We found that pretreatment of INS-1 cells with PCS extract inhibited the phosphorylation of JNK and p38 MAPK and also decreased the cleavage of PARP and caspase- 3 proteins, which are major apoptotic signaling molecules [32]. This suggests that PCS extract has antiapoptotic effect in betacells.

To investigate the protective mechanisms of PCS extract, we used an $\mathrm{H}_{2} \mathrm{O}_{2}$-induced apoptosis cell model. Our results demonstrated that treatment of INS-1 cells with $\mathrm{H}_{2} \mathrm{O}_{2}$ significantly increased intracellular ROS levels, and PCS extract inhibited $\mathrm{H}_{2} \mathrm{O}_{2}$-induced ROS generation. Cells are protected from oxidative stress by endogenous antioxidative enzymes such as GPX, SOD, and HO-1. Overexpression of antioxidant enzymes in the beta-cells of transgenic mice is extremely effective in preventing STZ-induced beta-cell death [22]. We observed that treatment of INS-1 cells with PCS extract increased the activity of GPX and SOD and increased the expression of $\mathrm{HO}-1$ protein. In addition, phosphorylation of AMPK which is a well-known metabolic regulator was also increased by PCS treatment. This suggests that PCS extract reduces ROS by increasing the production of antioxidant enzymes, thus reducing oxidative stress.

ROS are by-products of normal cellular oxidative stress process. Most ROS are generated in the mitochondria. Several studies have demonstrated that the ROS generation performs a crucial function in promoting proapoptotic activity [7]. Mitochondrial proapoptotic signaling is related to caspase-3 and PARP activation [32], which was reduced by PCS extract in our study. Our previous study showed that PCS extract has a mitochondrial protective effect in hepatocytes [24]. Therefore, it is thought that PCS extract may have a mitochondrial protective effect in pancreatic beta-cells. Further studies are required to discover the detailed mechanisms.

We found that PCS extract prevented $\mathrm{H}_{2} \mathrm{O}_{2}$-induced beta-cell apoptosis in INS-1 cells. Bakuchiol, psoralen, and isopsoralen are major components of PCS extract and are the most studied components. We found that pretreatment of INS-1 cells with purified psoralen or isopsoralen (which are both coumarins), but not bakuchiol, inhibited $\mathrm{H}_{2} \mathrm{O}_{2}$ induced cell death. According to our liquid chromatographymass spectrometry data, the PCS extract used in this study contained both psoralen and isopsoralen, suggesting that these coumarins are among the active components of PCS extract with respect to beta-cell protection. In our previous study, bakuchiol showed protective effects on $\mathrm{H}_{2} \mathrm{O}_{2}$-induced oxidative stress in hepatocytes [24], whereas it was ineffective in beta-cells in the present study. This suggests that different mechanisms might be involved in the protective effects against oxidative stress-induced apoptosis in insulin producing beta-cells (coumarin-mediated) compared with other cell types such as hepatocytes (bakuchiol-mediated).

In conclusion, PCS extract showed protective effects against STZ-induced pancreatic beta-cell damage in vivo and $\mathrm{H}_{2} \mathrm{O}_{2}$-induced apoptosis in vitro. Our data suggest that PCS extract has beneficial effects in pancreatic betacell destruction through its antioxidant and antiapoptotic actions. PCS extract may be a beneficial plant-based dietary component to counteract oxidative stress-induced beta-cell damage.

\section{Abbreviations \\ GPX: $\quad$ Glutathione peroxidase \\ HO: Heme oxygenase \\ MAPK: Mitogen-activated protein kinase \\ pAMPK $\alpha$ : Phosphorylated 5' AMP-activated protein kinase $\alpha$ \\ PARP: Poly(ADP-ribose) polymerase \\ PBS: $\quad$ Phosphate buffered saline \\ PCS: $\quad$ Psoralea corylifolia seed \\ pJNK: $\quad$ Phosphorylated c-Jun N-terminal \\ kinase \\ ROS: $\quad$ Reactive oxygen species \\ SOD: $\quad$ Superoxide dismutase \\ STZ: Streptozotocin.}

\section{Conflict of Interests}

The authors declare that there is no conflict of interests regarding the publication of this paper.

\section{Acknowledgments}

This study was supported by Grant (K11101) from Korea Institute of Oriental Medicine and in part by a Grant from the Korean Health Technology R\&D Project, Ministry of Health and Welfare, Korea (A102060). We thank Dr. Ann Kyle for editorial assistance.

\section{References}

[1] D. L. Eizirik and T. Mandrup-Poulsen, "A choice of death-the signal-transduction of immune-mediated beta-cell apoptosis," Diabetologia, vol. 44, no. 12, pp. 2115-2133, 2001.

[2] T. Mandrup-Poulsen, " $\beta$-cell apoptosis: stimuli and signaling," Diabetes, vol. 50, supplement 1, pp. S58-S63, 2001.

[3] D. Mathis, L. Vence, and C. Benoist, " $\beta$-cell death during progression to diabetes," Nature, vol. 414, no. 6865, pp. 792-798, 2001.

[4] H. E. Thomas, M. D. McKenzie, E. Angstetra, P. D. Campbell, and T. W. Kay, "Beta cell apoptosis in diabetes," Apoptosis, vol. 14, no. 12, pp. 1389-1404, 2009.

[5] R. P. Robertson, "Chronic oxidative stress as a central mechanism for glucose toxicity in pancreatic islet beta cells in diabetes," The Journal of Biological Chemistry, vol. 279, no. 41, pp. 42351-42354, 2004.

[6] M. Prentki and C. J. Nolan, "Islet $\beta$ cell failure in type 2 diabetes," The Journal of Clinical Investigation, vol. 116, no. 7, pp. 1802-1812, 2006.

[7] G. Drews, P. Krippeit-Drews, and M. Düfer, "Oxidative stress and beta-cell dysfunction," European Journal of Physiology, vol. 460, no. 4, pp. 703-718, 2010.

[8] C. Huang, W.-Y. Ma, A. Goranson, and Z. Dong, "Resveratrol suppresses cell transformation and induces apoptosis through a 
p53-dependent pathway," Carcinogenesis, vol. 20, no. 2, pp. 237242, 1999.

[9] S. Golbidi, M. Badran, and I. Laher, "Diabetes and alpha lipoic acid," Front Pharmacol, vol. 2, article 69, 2011.

[10] R. Rahimi, S. Nikfar, B. Larijani, and M. Abdollahi, "A review on the role of antioxidants in the management of diabetes and its complications," Biomedicine \& Pharmacotherapy, vol. 59, no. 7, pp. 365-373, 2005.

[11] G. Jiangning, W. Xinchu, W. Hou, L. Qinghua, and B. Kaishun, "Antioxidants from a Chinese medicinal herb-Psoralea corylifolia L," Food Chemistry, vol. 91, no. 2, pp. 287-292, 2005.

[12] N. R. Prasad, C. Anandi, S. Balasubramanian, and K. V. Pugalendi, "Antidermatophytic activity of extracts from Psoralea corylifolia (Fabaceae) correlated with the presence of a flavonoid compound," Journal of Ethnopharmacology, vol. 91, no. 1, pp. 2124, 2004.

[13] W. M. Yang, M. S. Chang, and S. K. Park, "Effects of Psoralea corylifolia on the CAMP-responsive element modulator (CREM) expression and spermatogenesis in rats," Journal of Ethnopharmacology, vol. 117, no. 3, pp. 503-506, 2008.

[14] J. Guo, H. Wu, X. Weng, J. Yan, and K. Bi, "Studies on extraction and isolation of active constituents from Psoralen corylifolia L. and the antitumor effect of the constituents in vitro," Zhong Yao Cai, vol. 26, no. 3, pp. 185-187, 2003.

[15] N. A. Khatune, M. E. Islam, M. E. Haque, P. Khondkar, and M. M. Rahman, "Antibacterial compounds from the seeds of Psoralea corylifolia," Fitoterapia, vol. 75, no. 2, pp. 228-230, 2004.

[16] S. Yin, C.-Q. Fan, Y. Wang, L. Dong, and J.-M. Yue, "Antibacterial prenylflavone derivatives from Psoralea corylifolia, and their structure-activity relationship study," Bioorganic \& Medicinal Chemistry, vol. 12, no. 16, pp. 4387-4392, 2004.

[17] H. Cho, J.-Y. Jun, E.-K. Song et al., "Bakuchiol: a hepatoprotective compound of Psoralea corylifolia on tacrine-induced cytotoxicity in hep G2 cells," Planta Medica, vol. 67, no. 8, pp. 750-751, 2001.

[18] E.-J. Park, Y.-Z. Zhao, Y.-C. Kim, and D. H. Sohn, "Protective effect of (S)-bakuchiol from Psoralea corylifolia on rat liver injury in vitro and in vivo," Planta Medica, vol. 71, no. 6, pp. 508$513,2005$.

[19] Y. Wang, C. Hong, C. Zhou, D. Xu, and H.-B. Qu, "Screening antitumor compounds psoralen and isopsoralen from Psoralea corylifolia L. seeds," Evidence-Based Complementary and Alternative Medicine, vol. 2011, Article ID 363052, 7 pages, 2011.

[20] C.-R. Wu, C.-L. Chang, P.-Y. Hsieh, L.-W. Lin, and H. Ching, "Psoralen and isopsoralen, two coumarins of Psoraleae Fructus, can alleviate scopolamine-induced amnesia in rats," Planta Medica, vol. 73, no. 3, pp. 275-278, 2007.

[21] C. L. Rohlfing, R. R. Little, H.-M. Wiedmeyer et al., "Use of $\mathrm{GHb}\left(\mathrm{HbA}_{\mathrm{lc}}\right)$ in screening for undiagnosed diabetes in the U.S. population," Diabetes Care, vol. 23, no. 2, pp. 187-191, 2000.

[22] M. Kinalski, A. Śledziewski, B. Telejko, W. Zarzycki, and I. Kinalska, "Antioxidant therapy and streptozotocin-induced diabetes in pregnant rats," Acta Diabetologica, vol. 36, no. 3, pp. 113-117, 1999.

[23] S. Jan, T. Parween, T. O. Siddiqi, and M. Mahmooduzzafar, "Anti-oxidant modulation in response to gamma radiation induced oxidative stress in developing seedlings of Psoralea corylifolia L.," Journal of Environmental Radioactivity, vol. 113, pp. 142-149, 2012.
[24] E. Seo, Y. S. Oh, D. Kim, M.-Y. Lee, S. Chae, and H.-S Jun, "Protective role of Psoralea corylifolia L. seed extract against hepatic mitochondrial dysfunction induced by oxidative stress or aging," Evidence-Based Complementary and Alternative Medicine, vol. 2013, Article ID 678028, 9 pages, 2013.

[25] H.-C. Lee and Y.-H. Wei, "Oxidative stress, mitochondrial DNA mutation, and apoptosis in aging," Experimental Biology and Medicine, vol. 232, no. 5, pp. 592-606, 2007.

[26] H. Haraguchi, J. Inoue, Y. Tamura, and K. Mizutani, "Antioxidative components of Psoralea corylifolia (Leguminosae)," Phytotherapy Research, vol. 16, no. 6, pp. 539-544, 2002.

[27] H. Kaneto, T.-A. Matsuoka, N. Katakami et al., "Oxidative stress and the JNK pathway are involved in the development of type 1 and type 2 diabetes," Current Molecular Medicine, vol. 7, no. 7, pp. 674-686, 2007.

[28] S.-H. Lee, S.-M. Kang, S.-C. Ko, M.-C. Kang, and Y.-J. Jeon, "Octaphlorethol A, a novel phenolic compound isolated from Ishige foliacea, protects against streptozotocin-induced pancreatic $\beta$ cell damage by reducing oxidative stress and apoptosis," Food and Chemical Toxicology, vol. 59, pp. 643-649, 2013.

[29] O. Coskun, M. Kanter, A. Korkmaz, and S. Oter, "Quercetin, a flavonoid antioxidant, prevents and protects streptozotocininduced oxidative stress and $\beta$-cell damage in rat pancreas," Pharmacological Research, vol. 51, no. 2, pp. 117-123, 2005.

[30] T.-H. Lu, C.-C. Su, Y.-W. Chen et al., "Arsenic induces pancreatic $\beta$-cell apoptosis via the oxidative stress-regulated mitochondria-dependent and endoplasmic reticulum stresstriggered signaling pathways," Toxicology Letters, vol. 201, no. 1, pp. 15-26, 2011.

[31] Y. Son, Y.-K. Cheong, N.-H. Kim, H.-T. Chung, D. G. Kang, and H.-O. Pae, "Mitogen-activated protein kinases and reactive oxygen species: how can ROS activate MAPK pathways?" Journal of Signal Transduction, vol. 2011, Article ID 792639, 6 pages, 2011.

[32] K.-C. Chang, C.-C. Hsu, S.-H. Liu et al., "Cadmium induces apoptosis in pancreatic beta-cells through a mitochondriadependent pathway: the role of oxidative stress-mediated c-Jun N-terminal kinase activation," PLoS ONE, vol. 8, no. 2, article e54374, 2013. 


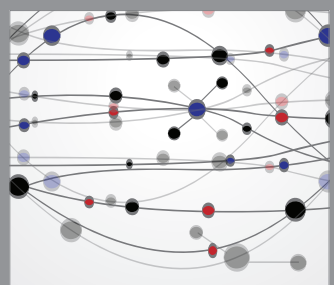

The Scientific World Journal
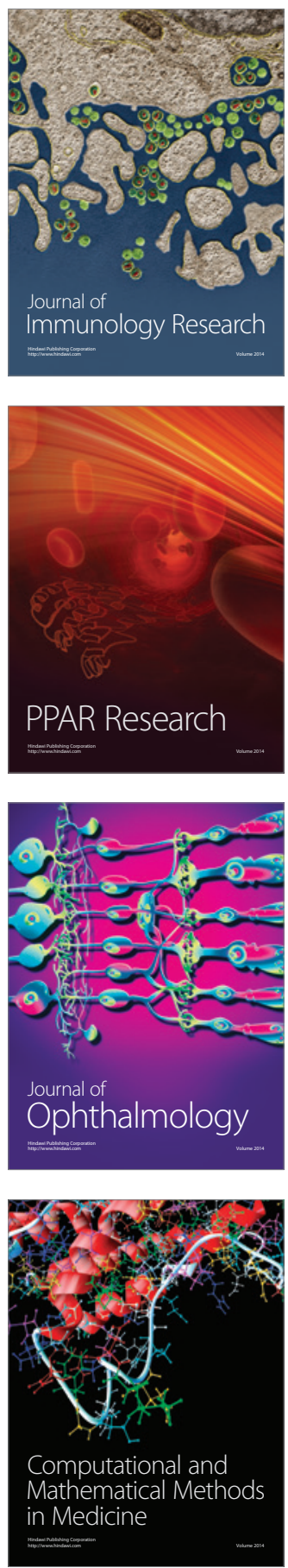

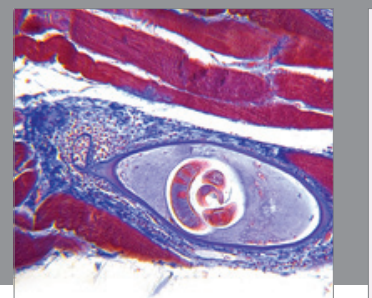

Gastroenterology

Research and Practice
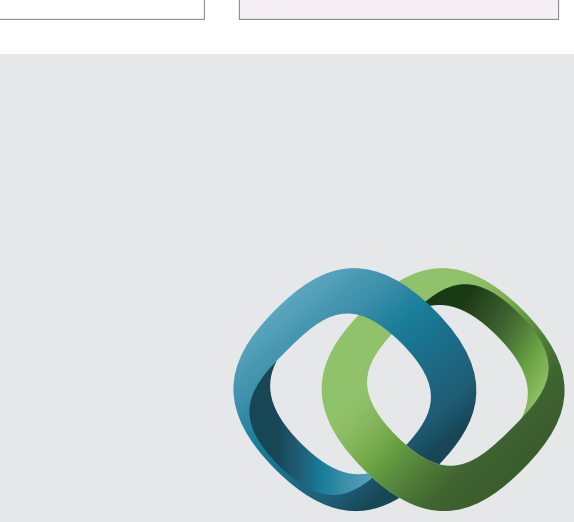

\section{Hindawi}

Submit your manuscripts at

http://www.hindawi.com
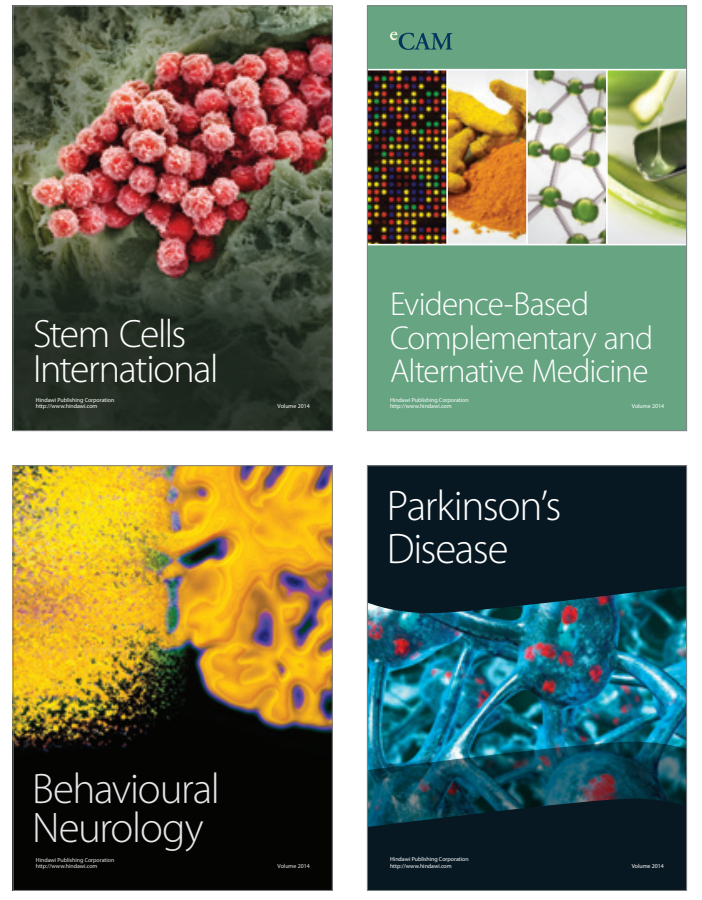
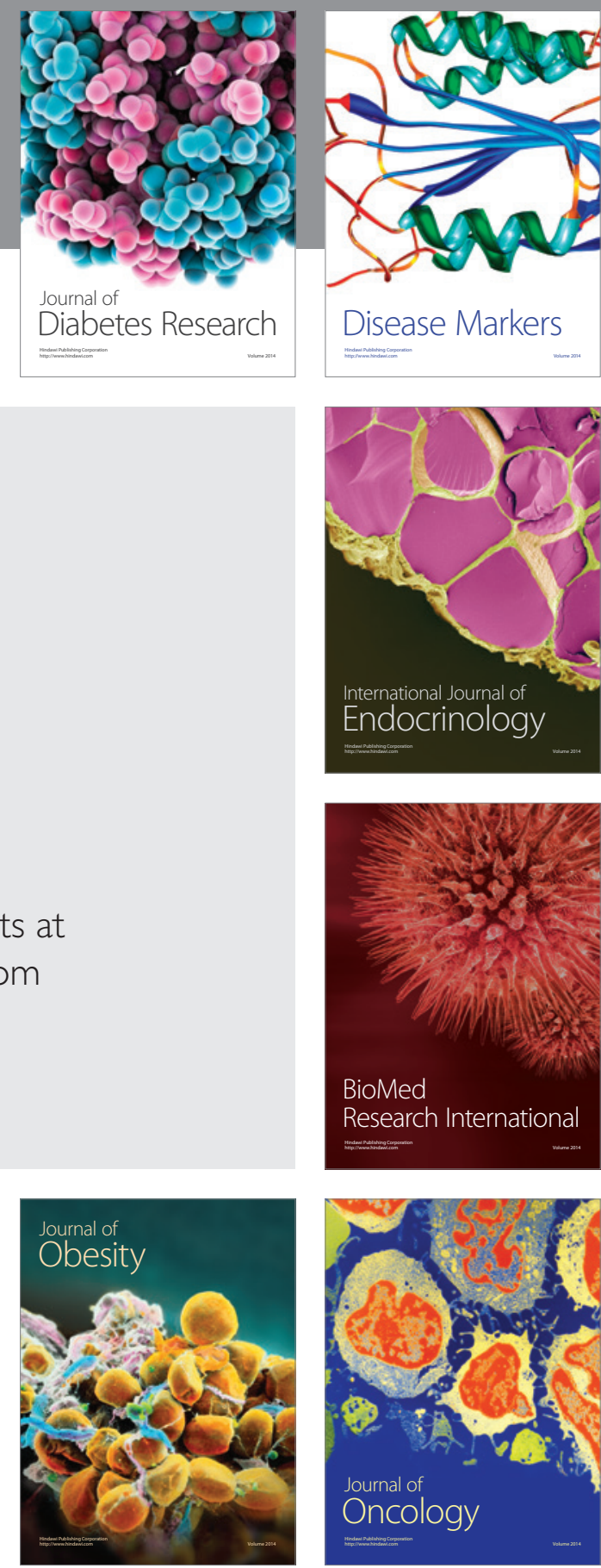

Disease Markers
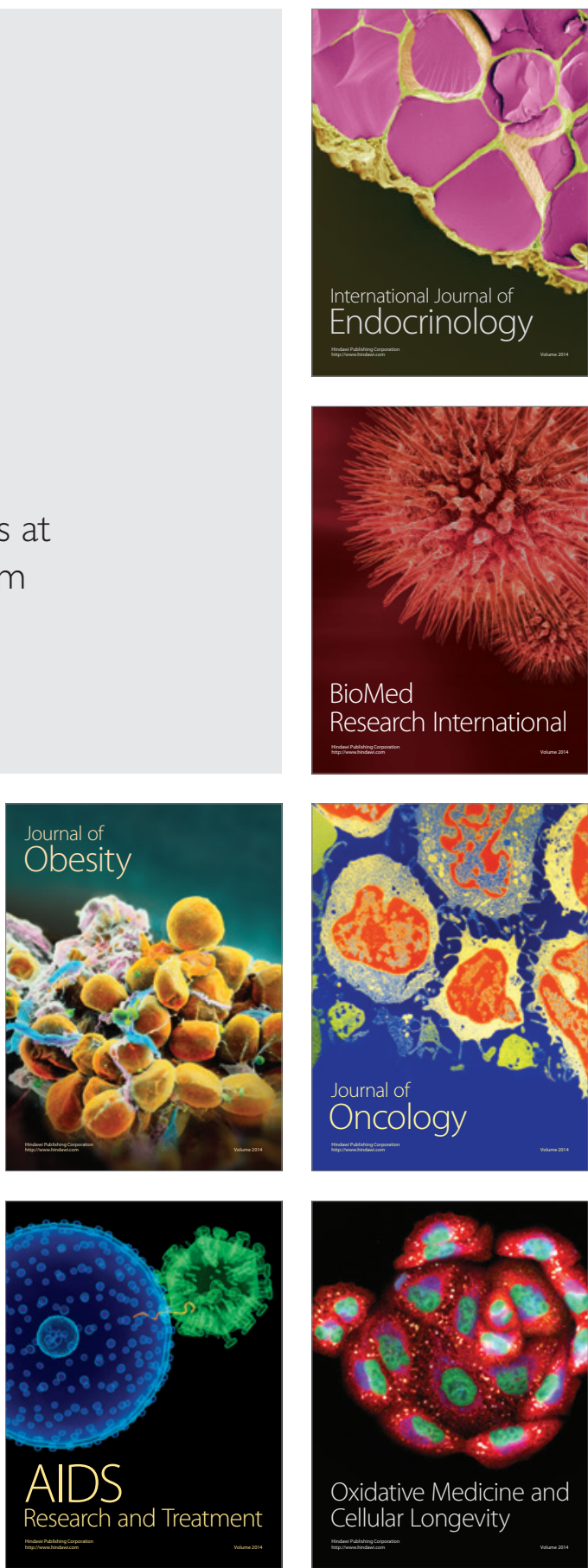